\title{
LA CASA COLONIAL POPULAR DE TOLUCA
}

\author{
$\mathbf{P} \mathbf{O}$ \\ VICTOR MANUEL VILLEGAS \\ Trabajo leído en la III Asamblea \\ del Congreso de Instituciones Cien- \\ tíficas y Culturales de la República, \\ que tuvo lugar en la ciudad de \\ Toluca del día 15 al 17 de febrero \\ de 1957.
}

DESDE que salió a la luz mi primer libro, sobre la herrería colonial de Toluca, ${ }^{1}$ ha sido motivo de constante meditación para mi el tema de la casa toluqueña. A simple vista parece que el problema no debería tomarse en serio, dado que en Toluca, aparentemente, la casa habitación no presenta características técnicas o estéticas que la hagan merecedora de un estudio siquiera ligero para encontrarle una clasificación adecuada, dentro de nuestra Historia de la Arquitectura colonial. Pero cuando ha quedado demostrado que la herrería colonial de mi ciudad de origen es, no obstante su modestia, tan abundante, de tan gran valor estético y que denota, además una gran habilidad en los obreros que la produjeron, se debe concluir, consecuentemente, que la arquitectura a que estaban destinados tales fierros forjados, debe tener esas cualidades - y las tienedentro de su misma sencillez y características propias, de tal modo que podrían encuadrarse dentro de alguno de los estilos o clasificaciones consagradas en la Historia del Arte colonial de México o, más bien, designarle un lugar propio.

1 Villegas, Víctor Manuel. Hierros Coloniales en Toluca, Toluca, Méx. 1942. 
Estas preocupaciones estéticas, no obstante ser tan personales, coinciden con las de otra rama de la Historia del Arte General, descubierta en el siglo xrx y afirmada satisfactoriamente en este siglo, $y$ aunque no resuelta del todo, es ya inquietante y motivo de estudios, controversias e investigaciones importantes; ella es: el Arte Popular.

$\mathrm{Y}$ hasta tal punto el problema es reciente e importante que, en un siglo de estudio, todavía no se definen satisfactoriamente las fronteras entre el arte culto y el arte popular, hasta donde llegan la Historia, la Estética y los conocimientos científicos y artísticos tradicionales y que forman el acervo cultural de la humanidad. Hay quienes niegan que tal arte popular exista como disciplina independiente, como no esté representada solamente por una serie de artes manuales, primitivas y aisladas o por manifestaciones arquitectónicas primigenias de los pueblos más incultos. Para el objeto de este estudio y aun cuando sea sólo convencionalmente, aceptamos las definiciones de Manuel B. Cossío, ${ }^{2}$ que son las que más se acomodan a él; para Cossío el arte popular "es claro y es sencillo, es ingenuo y modesto, es, sobre todo, abnegado y sin presuntuosos alardes de originalidad innovadora... elimina cuanto repugna a la castidad de su naturaleza original".

Por contraste y complementando las reflexiones anteriores, Juan Subias Galter, de la Real Academia de San Fernando, hace notar ${ }^{3}$ que el "arte popular se presenta con tanto mayor carácter en las naciones que poseen una mayor riqueza en arte erudito", y sus afirmaciones parecen que lindan con lo paradójico cuando transcribe las afirmaciones de Aranzadi : "lo que empezó por tener interés local, regional, nostálgico, romántico o pintoresco, acaba por presentarse como un problema cuya solución interesa a la historia de la civilización".

Asimismo, de aparentemente sencillo el estudio de la casa popular toluqueña se torna en complejo, $\mathrm{y}$ tanto más importante, cuanto que se da el caso de que en Toluca, del siglo XVI al xIx, no existe otro tipo de arquitectura que no sea la arquitectura popular concebida con las normas anotadas y también se da la aparente paradoja de que nos habla Aranzadi, cuando sabemos, sin lugar a duda, que antes de que el gran estilo churrigueresco en Nueva España tuviese plena realización en el gigantesco

2 Gaiter, Juan Subias. El Arte Popular en España. Barcelona, 1948. Pp. 11, 10 y 7 , respectivamente.

3 Galter, Juan Subias. $O p$. cit.

4 Citado por Subias Galter. 
retablo de los Reyes de la Catedral Metropolitana, se había iniciado ya en los tres primorosos altares de la sacristía del humilde convento franciscano de la Asunción de Toluca.

Nuestras afirmaciones sobre la casa popular toluqueña encuentran otro apoyo en Vicente Lampérez y Romea, ${ }^{\mathbf{5}}$ cuando estudia la arquitectura civil española y con las diversas clases de edificios forma dos grandes grupos: el primero para la Arquitectura Privada, y el segundo para la Arquitectura Pública. Con el primer grupo forma dos subdivisiones: a) para la arquitectura rústica y popular. Cuando trata de la casa popular, entendida literalmente como casa del pueblo "por extensión aatural", la enmarca junto a la arquitectura rústica, porque aun cuando la ubica dentro de las ciudades, considera que por servir de vivienda a labradores o gentes humildes, por ende tiene "iguales o análogas necesidades que la casa rústica"; de esta última dice:

"Pobre y humilde siempre, y destinada a servicios que la Naturaleza ha hecho invariables en cierto modo, la vivienda rústica no experimenta en su desarrollo, a través de los tiempos, las variantes que otra clase de edificios. Las de los estilos la afectan escasamente, pues no es el Arte (?) la característica de tales construcciones. $\mathrm{Y}$ el concepto cronológico tiene, por aquella invariabilidad, muy relativo valor en el estudio de las construcciones rústicas.

Lo tiene, en cambio, enorme, la geografía. Siendo el pais y el clima factores integrables de la producción agrícola y de la vida campestre, la arquitectura que haya de satisfacer sus necesidades habrá de adaptarse al medio, obrando con los materiales que le da el suelo y en la disposición a que le obligue el cielo, único modo de crear una arquitectura barata ? propia."

Arquitectura barata y propia es la de la casa toluqueña de los siglos Xvi al XIx, pero no por ello sujeta simplemente a la geografía, sino con severa dignidad que la sitúa dentro del arte popular auténtico e indudable; tiene gran personalidad, que se entenderá mejor si se pasa revista cuidadosa a las características sociales e históricas que la definen y se manifiestan en sus construcciones típicas.

* $\quad * \quad *$

El Valle de Toluca, considerado como uno de los más grandes del mundo, quizá el más extenso, fue territorio poblado en la época precor-

5 Lampérez y Romea, Vicente. Arquitectura Civil Española. T. I, pp. 35 y 36. 
tesiana, hacia 1120 d. J. C., "desde la nebulosa Aztlán" por la tribu matlazinca o matlazinga, constituyendo un reino limitado en su gran extensión por Michoacán y el Anáhuac por los grandes conjuntos montañosos de la sierra de Tajimaroa y de Maravatío, hasta el Oriente con el Valle de México. Fue fundada la ciudad de Toluca como se concebían los primigenios caseríos indígenas, con construcciones endebles que contrastaban con la solidez de sus templos en los que se esmeraba la técnica $y$ el arte de esos pueblos y donde el indígena entrenaba sus hábiles manos y maduraba en gusto artístico lo mismo en las artes suntuarias que en la escultura, la pintura y la arquitectura.

Sometida la prepotente tribu matlazinca a la arrolladora fuerza política y guerrera de los mexica, se convierte en su tributaria, recibiendo, en cambio, su innegable influencia cultural más avanzada y que se revela en sus monumentos religiosos. Creemos, con Martín Luis Guzmán, en la España formadora de pueblos, en el genio político de Hernán Cortés y en la pureza evangélica de los primeros frailes que subieron a la mesa de Anáhuac. Toluca fue un gran campo de prueba para esas virtudes españolas, en donde la reciedumbre de los más fuertes trabajadores y menos codiciosos peninsulares tuvieron que enfrentarse al cultivo de la tierra y de la cría del ganado en un clima hostil, frío, con el nítido ambiente que proporciona una enrarecida atmósfera de altiplano que, en cambio, "nunca tuvo los altibajos que acompañaron el desarrollo de otras poblaciones, villas y ciudades, donde la minería un día daba y otro quitaba", dice Velázquez. "La gran habilidad política del conquistador Don Hernando termina con las primeras épocas de la más cruel esclavitud de los indios y existen pruebas de su prudencia, habilidad e interés por estas tierras cuando, muy probablemente, como advierte Salinas, ${ }^{7}$ tal vez sirvió de padrino al cacique matlatzinca que llevó su propio apellido, Cortés; quizá en las visitas que Don Hernando hizo a la casa del mismo en los frecuentes viajes del conquistador a Toluca. De las buenas relaciones de estos personajes y los primeros franciscanos residentes en Toluca no queda duda, cuando sabemos que el cacique Juan Cortés Coyotzin cedió las tierras y dinero para la erección del convento en el lugar que había de ser, desde entonces hasta ahora, el corazón de la ciudad. Por p. 47.

6 Citado por Colín, Mario. Toluca. Crómicas de una ciudad. México, 1955,

7 Salinas, Miguel. Datos para la historia de Toluca. México, 1927, p. 52. 
tales bienes los franciscanos agradecidos hicieron al indígena patrono de la iglesia y del monasterio.

La influencia franciscana en Toluca es tan importante como tal vez en ningún lugar de la Nueva España y está documentada desde sus primeros tiempos hasta fines del siglo xvrr. De ella se destacan las grandes personalidades de fray Jerónimo de Mendieta; fray Juan de Torquemada, quien escribió en el monasterio tolucense el libro xIII de su Monarquia Indiana; fray José Cillero, quien hasta ahora resulta el primer arquitecto que, construyendo a la moderna, edificó en Toluca los primeros retablos churriguerescos de que se tiene noticia. La personalidad más relevante y decisiva para nuestra ciudad lo fue fray Andrés de Castro. Originario de Burgos, capital de Castilla la Vieja donde estudió Artes y Teología, continuó su esmerada educación en la Universidad de Salamanca bajo la dirección de ilustres franciscanos y llegó a Toluca en 1542, siendo el primero en estudiar y saber el idioma matlatzinca. En los treinta y cinco años que vivió en Toluca su personalidad relevante está ligada a la vida de la orden seráfica en todos sus éxitos, desde la erección de las primeras construcciones, en donde, por su cuidadosa preparación, fue factor importante, hasta en las intervenciones de mayor pureza evangélica, de las que nos da noticias conmovedoras el padre Mendieta. Toluca en sus primeros tiempos gira fundamentalmente dentro de la órbita franciscana, es, por decirlo de una vez, el monasterio Franciscano, y, para los indios, fray Andrés de Castro es "el único que sabía comprenderlos", en titánica e increíble labor de cristianización y asistencia espiritual y material.

No es de extrañar, por lo tanto, que, sin excepción todas las construcciones toluqueñas importantes o no, tengan el sello de los primeros edificios franciscanos, tanto en la concepción de sus plantas como en los alzados, como en las cubiertas y en todos los detalles. La arquitectura en Toluca, en suma, debería ser én poco menos de tres siglos arquitectura franciscana, aun dentro de la exhuberancia barroca churrigueresca o de la barroca italianizante del llamado estilo neoclásico.

Para todos los indios de la Nueva España hábiles arquitectos, escultores, canteros, albañiles, entalladores y carpinteros, la presencia de las herramientas de hierro los colocó en ventaja sobre los propios obreros españoles, pero ningún descubrimiento sería para ellos más trascendental y definitivo que el conocimiento del arco de dovelas y su consecuencia lógica, la bóveda. $\mathrm{El}$ poder increíble y mágico de esta invención, la más importante en la historia de la arquitectura de todos los tiempos, nos 
lit (iescribe con eloctente sencillez franciscana fray Jerónimo de Mendieta: ${ }^{8}$

"En los oficios que de antes sabian se perfeccionaron los indios después que vieron las obras que hacian los españoles. Los canteros, que eran curiosos en la escultura (como queda dicho), y labraban sin hierro con solas piedras cosas muy de ver, después que tuvieron picos y escodas y los demás instrumentos de hierro, y vieron obras gue los nuestros hacían, se aventajaron en gran manera, y así hacen y labran arcos redondos, escacianos $y$ terciados, portadas y ventanas de mucha obra, $y$ cuantos romanos $\mathrm{y}$ bestiones han visto, todo lo labran $\mathrm{y}$ han hecho muchas muy gentiles iglesias y casas para españoles. Lo que ellos no habían alcanzado y tuvieron en mucho cuando lo vieron, fue hacer bóvedas, $y$ cuando se hizo la primera (que fue la capilla de la iglesia vieja de S. Francisco de México, por mano de un cantero de Castilla), maravilláronse mucho los indios en ver cosa de bóveda, y no podían creer sino que al quitar de los andamios y cimbra, todo habia de venir abajo. $Y$ por esto cuando se vieron de quitar los andamios, ningumo de cllos osaba andar por debajo. Mas visto que quedaba firme la bóveda, luego perdieron el miedo. $\mathrm{Y}$ poco después los indios solos hicieron dos capiIlitas de bóveda, que todavía duran en el patio de la iglesia principal de Tlalcala, y después acá han hecho y cubierto muy excelentes iglesias de bóveda y casas de bóveda en tierras calientes. Los carpinteros, aunque cubrian de buena madera bien labrada las casas de los señores, y hacían otras obras de sus manos, es ahora muy diferente lo que hacen, porque labran de todas maneras de carpintería $\mathrm{i}$ imágenes de talla, y todo lo que los muy diestros artífices o arquitectos usan labrar. $\mathrm{Y}$ finalmente, esto se puede entender por regla general, que cuasi todas las buenas y curiosas obras que en todo género de oficios $y$ artes se hacen en esta tierra de Indias (a lo menos en la Nueva España), los indios son los que ejercitan y labran, porque los españoles maestros de los tales of icios, por maravilla hacen más que dar la obra a los indios y decirles cómo quieren que la hagan. $Y$ ellos la hacen tan perfecta, que no se puede mejorar."

El primer templo católico construído en Toluca, de que se tiene noticia, fue, según don Miguel Sảlinas ${ }^{9}$ la capilla de la Santa Cruz de los Otomites, y de la que solamente se conserva la portada.

Tal portada, si perteneció a ese templo, necesariamente corresponde a la de una capilla abierta, esto es, a un tipo característico de templos del siglo xvi en Nueva España, en donde solamente el sacerdote dis-

8 Fray Jerónimo de Mendieta. Historia Eclesiástica Indiana. T. III. México, p. 61 .

9 Salinas, Miguel. $O p$. cit., pp. 13 y 70. 
ponía de espacio cubierto para el culto cabe el pórtico, y las grandes multitudes que acudian a oír misa lo hacian en los atrios, frente a las arcadas de la capilla.

Fray Andrés de Castro ofició en esa capilla administrando la comunión dos años antes de su muerte en 1575, con motivo de la reconstrucción de dicho templo. Se sabe que - como en otros monumentos similares del siglo xvI-, el Marqués del Valle apareció en un retablo de la capilla con el cacique del lugar y un grupo de religiosos y de indios principales.

Tiene gran interés para el estudio de la casa popular de Toluca esta sencilla portada compuesta de tres arcos rebajados y moldurados de medio punto sobre columnas dóricas monolíticas. Las molduras de los arcos se coronan con el cordón franciscano y las columnas descansan sobre sencillos basamentos de piedra.

Otra capilla abierta más amplia, y posteriormente construída, que al mismo tiempo servía de portería, la describe así Salinas: ${ }^{10}$ "Estaba formado de cinco arcos: el central era el más alto; los laterales contiguos lo eran menos; y menos aún el primero y el último. Un poco más adentro se erguían otros cinco $\mathrm{y}$ al fin cerraba todo este departamento un muro, en cuyo centro se veía un altar, dedicado a San Francisco, donde se decía misa a los indios."

Los arcos de dicha capilla, de medio punto, peraltados, de gran sencillez, descansaban sobre recios pilares de mampostería de piedra rebocados con cal.

El cuadrante o lugar destinado a los anexos al templo de la Tercera Orden de San Francisco, junto al convento, tenía un patio donde los soportes eran columnas con fustes de madera sobre bases de piedra $y$ con zapatas de madera en lugar de capiteles.

Se tiene noticia que el primer templo de San Francisco estaba cubierto de madera con vigas de cedro con tablones de la propia madera forrada con gruesas láminas de plomo $\mathrm{y}$ al interior, al estilo árabe, con artesonados dorados y pintados de color rojo. No obstante, esta techumbre ligera se asentaba sobre sólidos muros, cosa muy común en los primitivos templos católicos del siglo xvr de la Orden Franciscana.

De la primitiva casa toluqueña con sentido europeo correspondiente al siglo xvi no queda ningún ejemplar, pero indudablemente que tales

10 Salinas, Miguel. Op. cit., p. 70. 
construcciones fueron provisionales, con muros gruesos de adobe, el material más barato y resistente, $y$ techadas con teja de tipo árabe, que aún se usa en las construcciones rústicas con terrados de madera $\mathrm{y}$ con escasos vanos al exterior.

La casa colonial toluqueña desde fines del siglo xvII puede considerarse en su solución de planta, alzados, vanos, apoyos y cubiertas como correspondiente en estilo a la casa popular andaluza donde, "el elemento esencial es el patio interior, corral o corte... Las grandes proporciones del patio, la esbelta galería (corredor le llaman en Toluca) que le rodea ... El hecho mismo de que en las ventanas no falte nunca la típica reja, subraya esta intención de mantener toda la vida de la casa orientada hacia adentro". 11

En un cuidadoso análisis de los elementos constitutivos de los materiales empleados y la técnica de la construcción y, sobre todo, en las formas simples y constantes, se indica inconfundiblemente su inspiración en las primeras construcciones del convento franciscano de la Asunción, que ya hemos descrito brevemente.

Materiales. Con la abundancia de piedra dura, de origen volcánico; arcilla de magnífica plasticidad, de la que se hacen excelentes adobes, ladrillos gruesos y delgados, y tejas, cal de buena calidad, muy buena arena, maderas abundantes de cedro, pino y oyamel, en un suelo firme, se dispuso de los materiales indispensables para la construcción típica, adecuada al clima frío de Toluca.

Plantas, Como se ha indicado, la planta más generalizada de la casa toluqueña se forma por un gran patio casi siempre cuadrado con una galería o corredor al que rodean las habitaciones comunicadas y con circulación interior por las necesidades del clima. El tipo más generalizado es el de una sola planta, aun cuando hay también de dos y nunca de más. El corral anexo es característico de casi todas las casas toluqueñas, hasta en la época moderna, donde se crian animales domésticos. El pozo es común en estos corrales.

Alzados. Los muros de las construcciones coloniales de Toluca, son casi siempre de adobe de 40 ctms. hasta $1 \mathrm{mt}$. o más de grueso, espesores que garantizan el aislamiento al exterior y dan lugar para alojar las puertas de madera -obscuros -, que cierran sobre las vidrieras y no estorban en el interior. Tales muros se asientan sobre cimientos de mam-

11 Subías Galter. Op. cit., p. 26. 
DOI: http://dx.doi.org/10.22201/iie.18703062e.1957.26.631

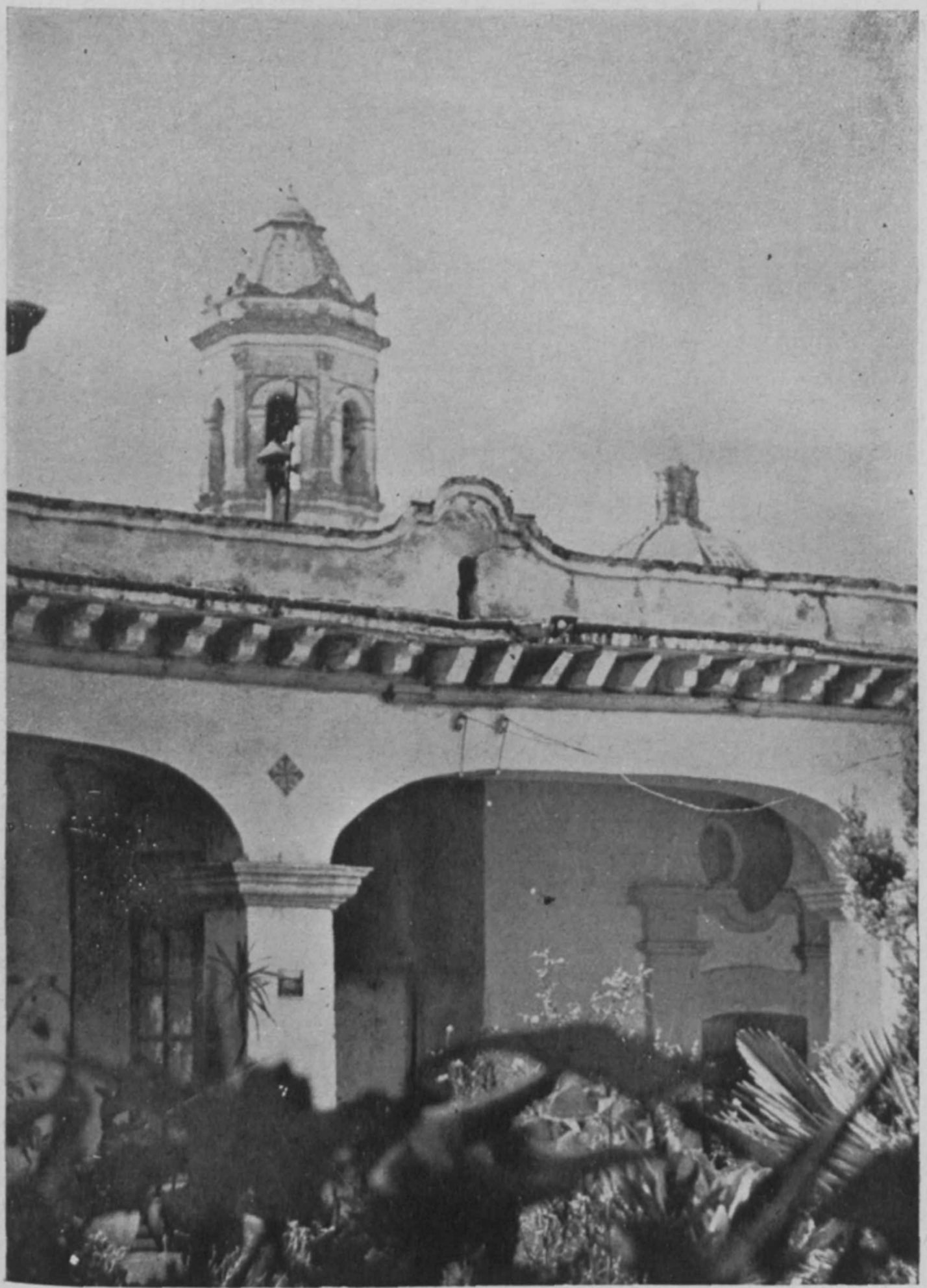

1. Casa de la esquina de Guerrero y Pedro Ascencio. Detalle del patio. 
DOI: http://dx.doi.org/10.22201/iie.18703062e.1957.26.631

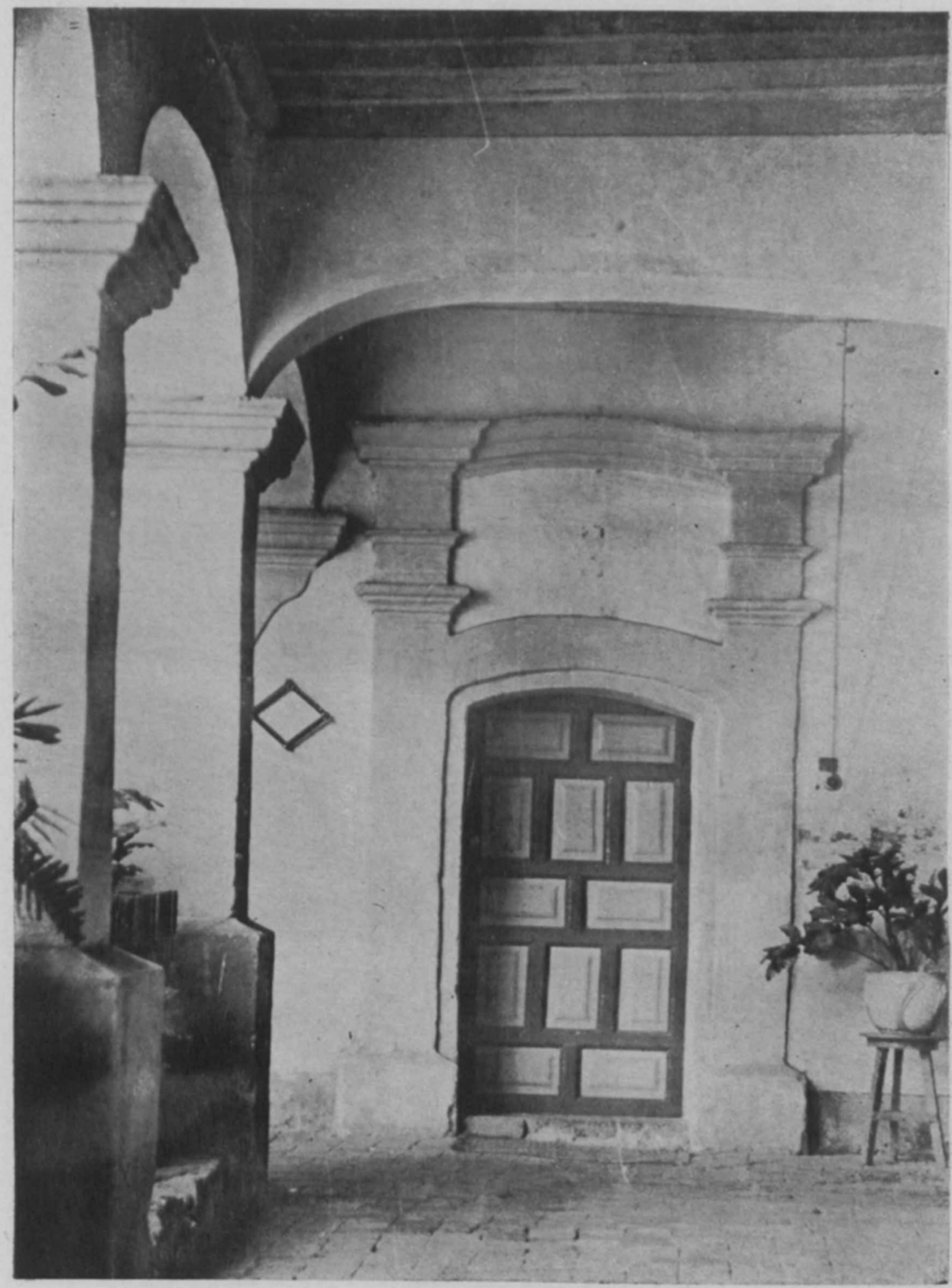

2. Casa de la esquina de Guerrero y Pedro Ascencio. Detalle del patio. 


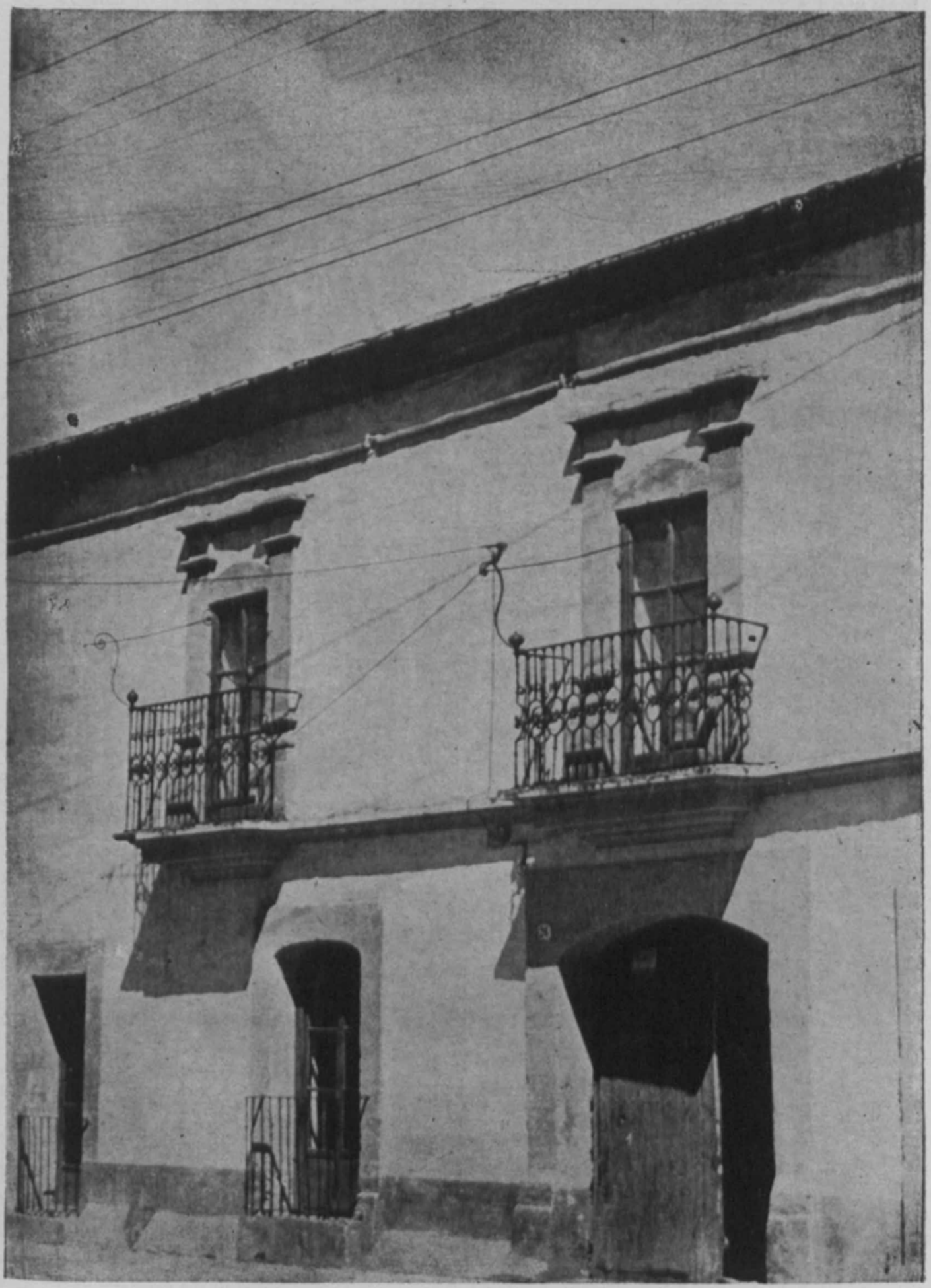

3. Fachada de una casa colonial de la calle de Villada. Siglo xvı 


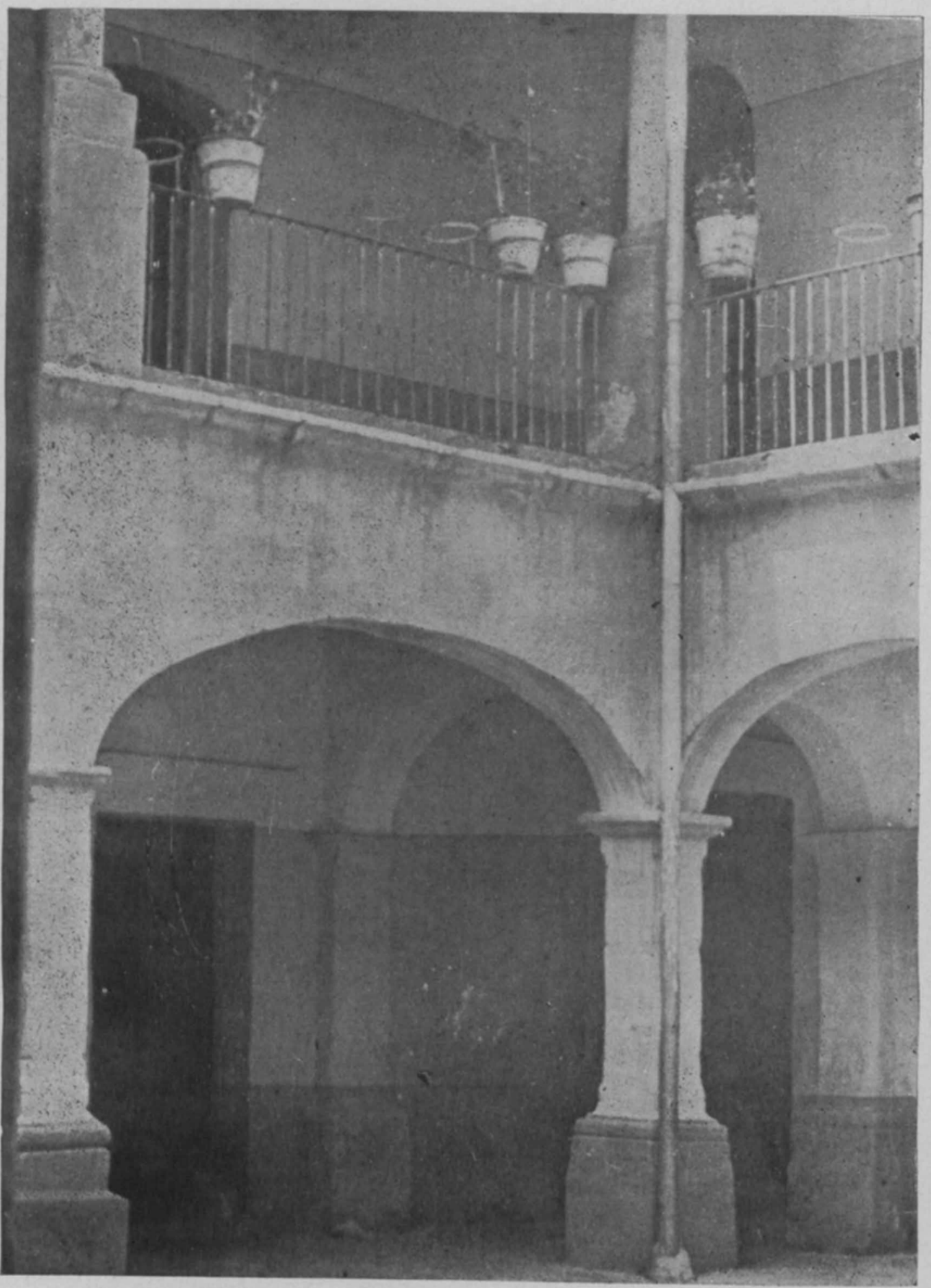

4. Casa colonial de la calle de Lerdo. Detalle del patio con pilares en la planta baja y columnas de madera en la segunda. 
DOI: http://dx.doi.org/10.22201/iie.18703062e.1957.26.631

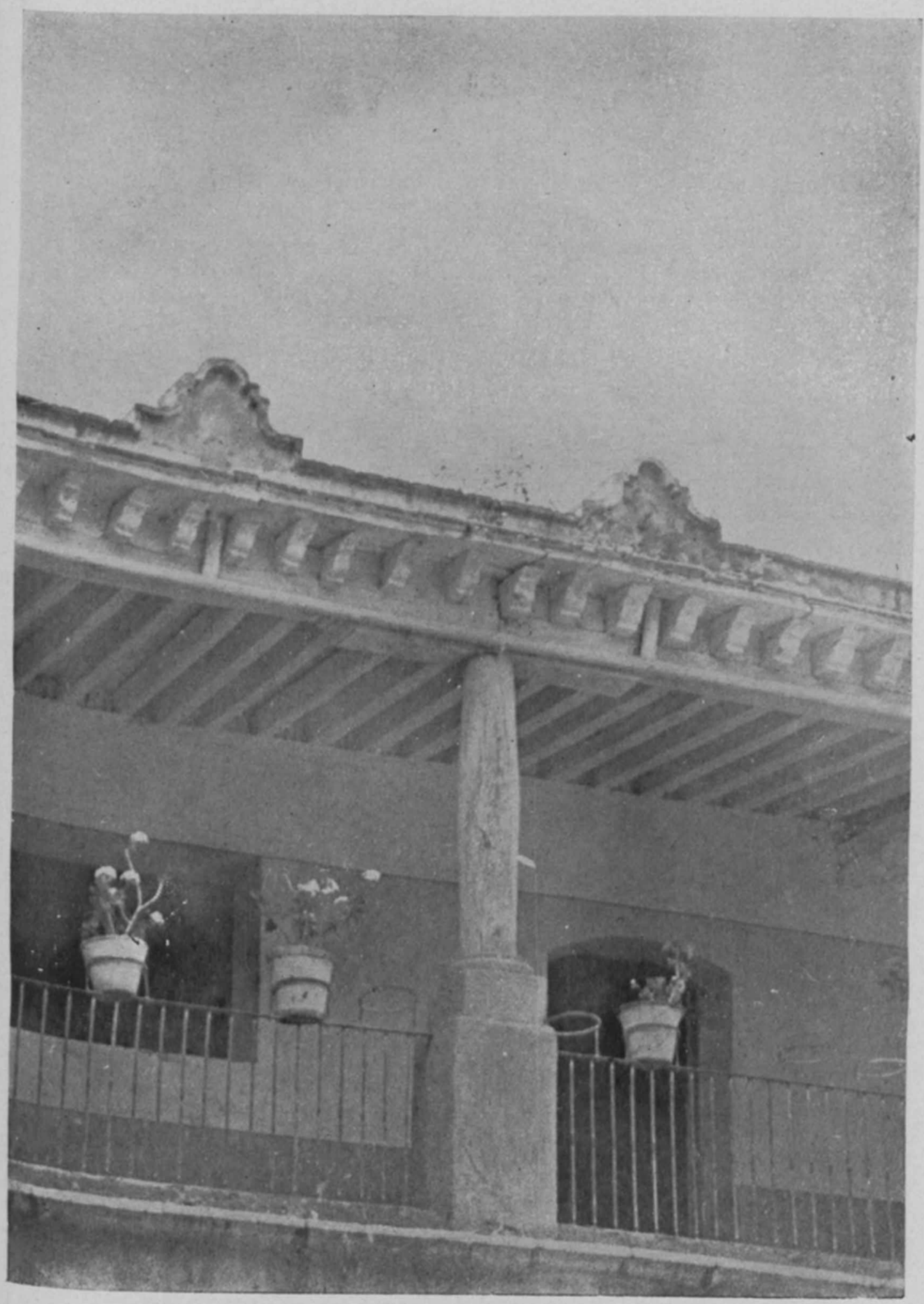

5. Casa colonial de la calle de Lerdo. Detalle de la planta alta; columnas de madera que corresponden a los pilares de la planta baja. 


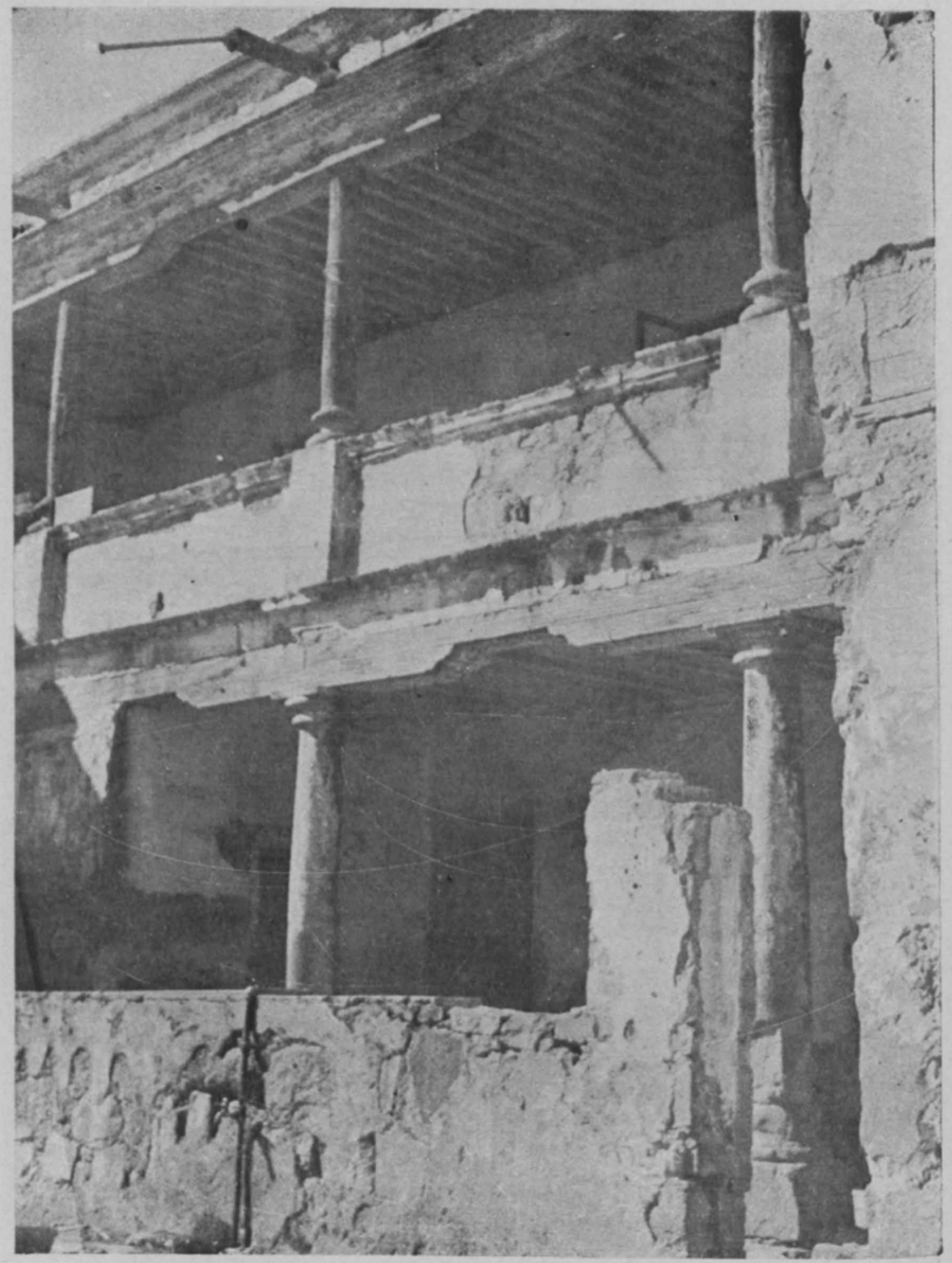

6. Casa colonial de la Avenida Independencia con columnas de piedra en la planta baja y de madera, sin capiteles, en la planta alta. 


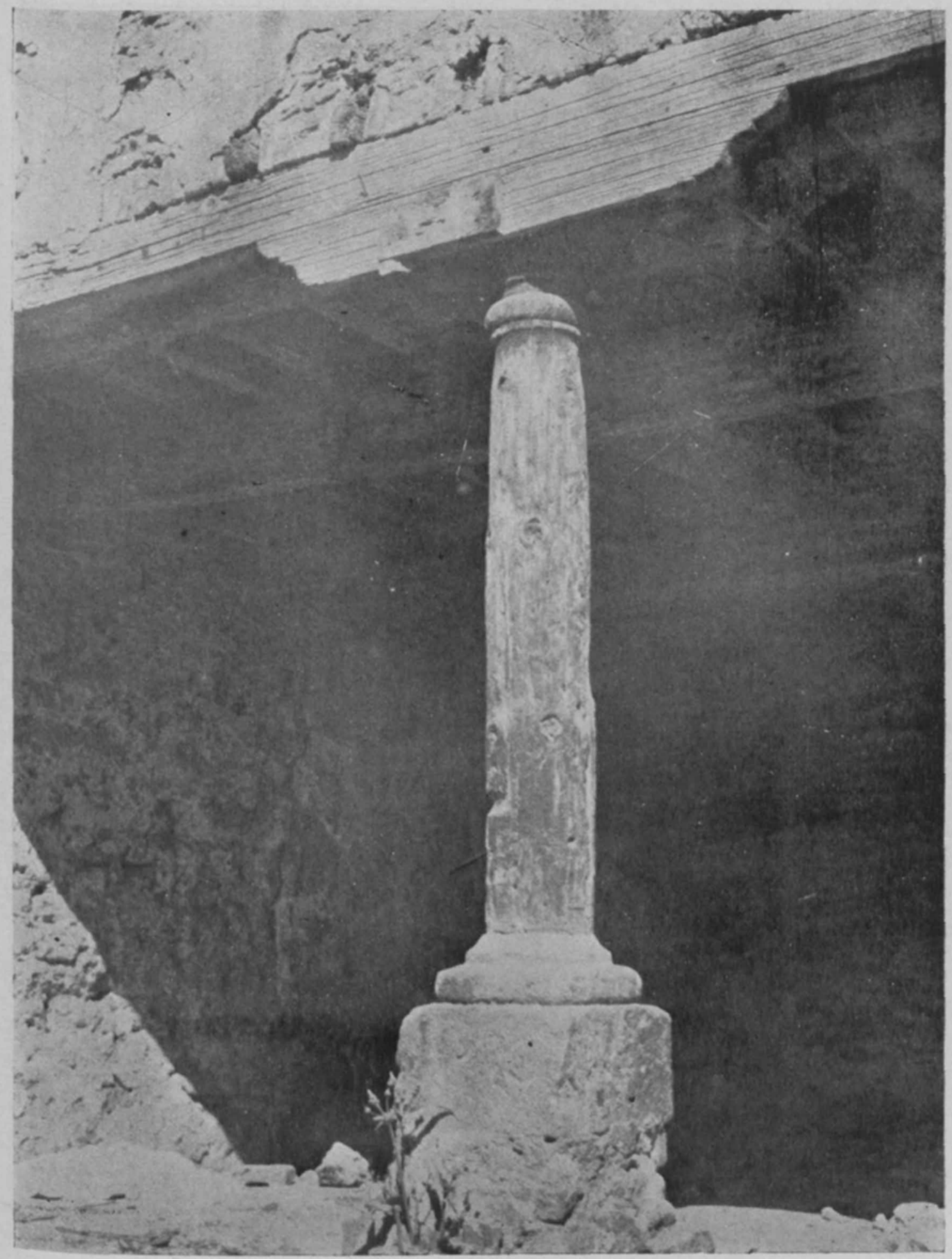

7. Casa colonial de la Avenida Independencia. Columnas de madera con capiteles torneados y zapatas, en la planta baja. 
DOI: http://dx.doi.org/10.22201/iie.18703062e.1957.26.631

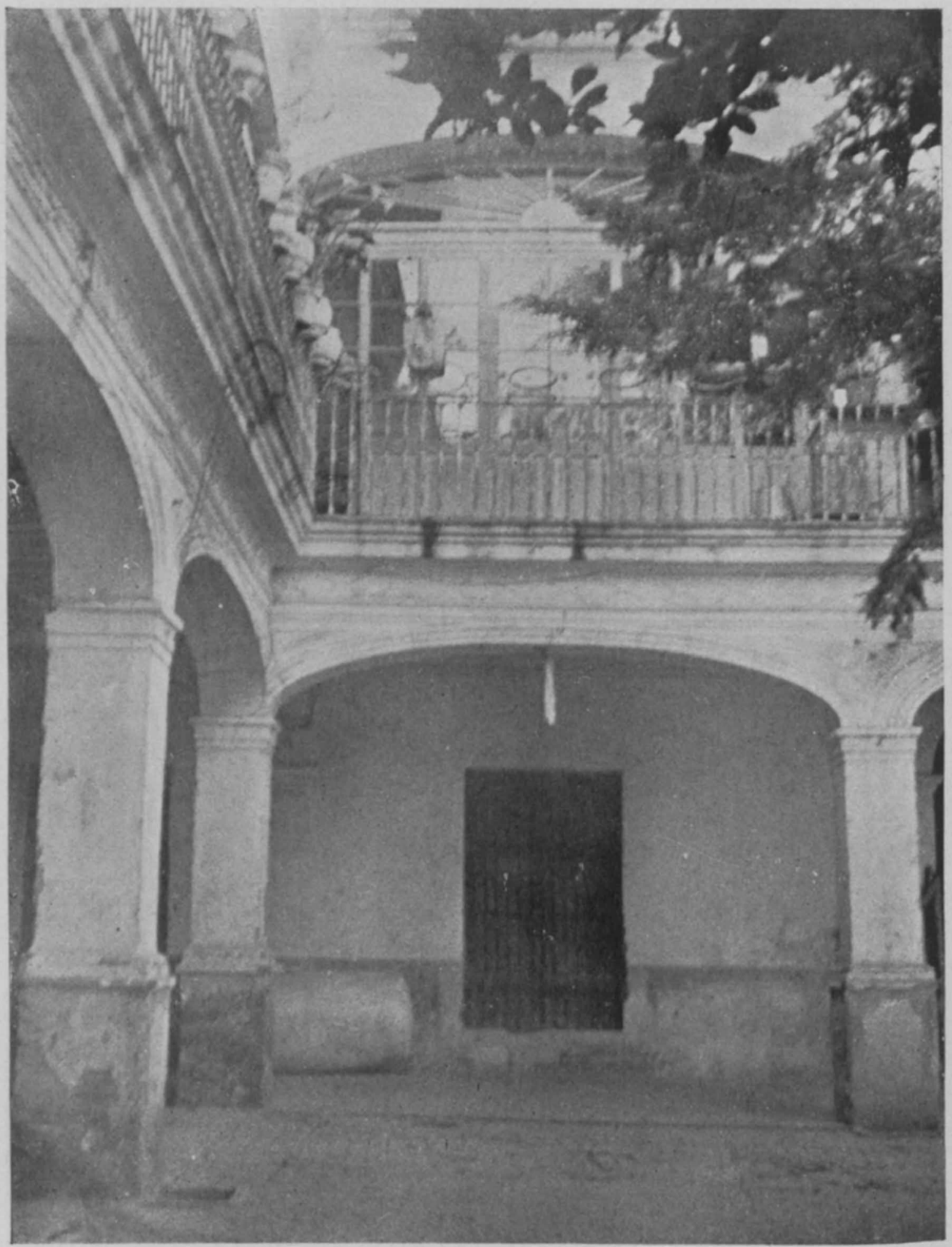

8. Patio de una casa de estilo neoclásico, del siglo xix. Detalle del patio con arcadas en sus dos plantas. 
posteria de piedra y algunas veces de materiales heterogéneos, mezclando el ladrillo con la piedra y el adobe donde el alarife ingeniosamente cmpleaba los materiales atendiendo a sus diversos grados de resistencia y sabiamente relacionados con los esfuerzos a que estaban sometidos.

Vanos y apoyos. Las ventanas y puertas más comunes eran de platabanda con cerramientos de madera en el interior para facilitar la fijación de las puertas o ventanas, y de ladrillo adovelado al exterior para detener el enjabelgado de cal y arena; en la época barroca estos cerramientos se formaron al exterior con arcos escarcianos también adovelados de ladrillo, con rejas, a veces muy sencillas, forjadas sin adornos, y con balcones en las casas de dos pisos. Los soportes de los corredores de los patios en casa de una sola planta varían. Existen desde el más sencillo que soporta la techumbre con columnas de madera sobre bases de piedra dura encima de muretes o pretiles, o simplemente sobre bancos de piedra o mampostería heterogénea enjabelgada de cal y arena, hasta los portales con arquerías de tres puntos o terciadas de elegante trazo, sobre pilares de sección cuadrada y de gran robustez, pasando por las columnas de fustes de piedra monolíticos del orden dórico. Estos tipos de apoyos son los elementos más característicos y típicos en las construcciones civiles toluqueñas, de inspiración inconfundible en las que hemos descrito dé las construcciones del monasterio franciscano y nunca copiadas servilmente. Cuando en las construcciones monumentales de las portadas conventuales exigen de los arcos mayor esbeltez, éstos son de medio punto, hasta peraltados, como en el caso de la antigua portería; en cambio, en los corredores toluqueños, sin perjuicio de los amplios claros que permiten el paso de la luz a las habitaciones, los arcos son de tres puntos: o terciados, para impedir que las techumbres sean excesivamente altas $y$ desproporcionadas donde la altura de la habitación la hace menos fria y más acogedora.

En algunos patios de casas de dos pisos, los tipos de soportes caraeterísticos se superponen usando de los pilares en la planta baja y columnás de madera en la segunda, o bien columnas monoliticas de piedra en el primer piso y de madera en el segundo.

La molduración renacentista de vanos y apoyos es, como en los monumentos de los franciscanos, del orden toscano. La mayor parte de paertas y ventanas están enmarcadas con las jambas características de la molduración colonial en Nueva España, siguiendo la técnica de ligar dichas jambas con los cerramientos y dinteles y unas veces con 
cornisamientos independientes, y en otros casos directamente con la cornisa general.

Cubiertas. De las cubiertas o techumbres, las más sencillas son las que simplemente se cubren de teja sobre cintas y morillos de oyamel con un terrado de tablas que compensa la inclinación del tejado y que sirve para guardar semillas o telebrejos. El tipo más generalizado de cubierta es el que se construye de la siguiente manera: sobre vigas de madera de oyamel se' colocan tejamanil o tablas de madera, encima de las cuales se pone tierra para aislar del sonido y la humedad. Sobre este terrado, que también sirve para dar los desniveles para el desagüe del techo, se coloca una capa de ladrillo muy bien junteado, que llevará el agua, en la época de lluvias, a los canalones que vierten el líquido directamente sobre el piso del patio, junto a los corredores, 0 al exterior sobre los empedrados de las calles.

Detalles. La casa de Toluca, no obstante su sobriedad característica, presenta detalles de buen gusto, que denotan el ingenio y: sentido artístico de nuestros modestos albañiles. Los rudimentarios entablementos se coronan con cornisuelos de moldurado muy simple que de tramo en tramo forman remates semicirculares, donde salen las gárgolas. El envigado de los techos sale al exterior hasta los patios, terminando las cabezas de las vigas en ménsulas con molduras que sostienen un pequeño alero que proteje del agua de lluvia a los corredores.

El estilo neoclásico se indica en la torre de la iglesia del Carmen terminada en 1814. Las constituciones de la orden de los Carmelitas, como las de los franciscanos, mandan que sus construcciones sean humildes y sobrias, así es como la casa toluqueña dè estilo neoclásico, con eșe ejemplo, sigue la tradición franciscana. El aspecto en el interior, por lo que se refiere a sus patios característicos, casi no varía y algunas veces tampoco el exterior, como en los famosos portales que circundan lo que fue el atrio del antiguo convento de los franciscanos. Solamente en algunos casos, por necesidad de seguir las proporciones vitrubianas, las casas ganan en altura para dar espacio al moldurado correcto de jambas, cerramientos y entablamentos, con detrimento de la temperatura en los interiores donde, por obtener mayor espacio, las habitaciones se tornan frias y demasiado altas.

Los habilísimos herreros y carpinteros toluqueños, pusieron la nota de elegancia en sus modestas casas y son admirables y variadas las obras de herreria y carpinteria. Los herreros que no disponían de fierro 
en abundancia se ingeniaron en usar éste al mínimo en las secciones de las varillas $y$ las soleras, sin perjuicio de las proporciones, la seguridad $y$ sobre todo, el buen gusto, hasta la aparición del fierro fundido a fines del siglo xIX.

Los carpinteros, que dispusieron de excelente material, hicieron gala de pericia y buen gusto, al grado de que, aún a la fecha, disponemos de ejemplares desde el estilo gotizante del siglo xvr hasta los complicados entablerados de las puertas y obscuros de los siglos xvII y xVIrI y las impecables molduras al gusto neoclásico.

Conclusiones. Para evitar conceptos que no podrían dejar de ser apasionados por nuestro amor al terruño, reproducimos las expresiones justas $\mathrm{y}$ equilibradas de Jean Dollfus: ${ }^{12}$

"El hombre del siglo $\mathrm{xx}$ se aparta y se libera cada día más de su medio natural, para multiplicar y activar sus relaciones con el universo humano tomando de él, y generalizándolas, las concepciones más ventajosas; de esta manera recompone, artificialmente, las materias que responden con el mejor beneficio a las nuevas exigencias de su bienestar. De ello resulta, en la construcción, el progresivo abandono de las formas seculares, acelerado por las ruinas de las últimas guerras mundiales y una cierta nivelación unificadora que legítimamente, en verdad, han hecho necesaria la expansión de la higiene y de las comodidades, tanto como la necesidad de construir de prisa y con poco gasto para alojar una población que crece sin cesar, pero que a menudo se establece a expensas del carácter local y del atrayente encanto que exhalaba. Puesto que los pueblos han de conservar su: carácter particular en las uniones que se están gastando, sería de desear que invenciones y tradiciones pudieran, en las formas de la vivienda, continuar conciliándose en un justo y armonioso equilibrio."

Las recomendaciones de Dollfus requieren una conveniente dirección $\mathrm{y}$ un ejemplo. Ambas cosas son complejas $\mathbf{y}$ difíciles. $\mathrm{El}$ doctor Justino Fernández, Director del Instituto de Investigaciones Estéticas -del que me cabe inmerecidamente el doble honor de formar parte $y$ de representar en la asamblea de este Congreso-, en reciente conferencia sustentada en el Palacio de Bellas Artes de la ciudad de México, señalaba la precaria calidad técnica y artística de las típicas construcciones de la Colonia Polanco de la capital —estilo "barroco-libanés" le llama Francisco de la Maza recordando la satírica denominación que

12 Dollfus, Jean. Aspectos de la Arquitectura Popular en el Mundo. Barcelona, $1955, \mathrm{p} . \mathrm{xv}$. 
inventó Rafael García Granados-, y hacia notar con toda justicia, cómo, quienes pensaban habitar en un ambiente señorial de gran lujo, sólo disfrutan en la realidad, de un arte popular de muy mala calidad.

Dentro del ámbito de la arquitectura moderna se peca en México también de inconvenientes y realizaciones inadecuadas para el medio y las necesidades nuestras.

En Toluca, en relación con la vivienda típica, se debe citar un caso que por inusitado y excepcional, constituye el mejor ejemplo de nuestro medio. Una de las más venerables construcciones toluqueñas $y$ mejor conservadas, ubicada en la esquina de las calles de Guerrero y Pedro Ascencio, fue adquirida recientemente por el conocido industrial toluqueño don Juan Salgado. La casa, que presentaba las inevitables marcas de más de trescientos años de existencia y todos los inconvenientes de la falta de comodidades de la vida moderna, fue cuidadosa y sabiamente restaurada, dotándola del confort de que carecía y a la fecha - sin perjuicio de su partido arquitectónico general y de sus características fundamentales-, seguramente constituye una construcción que, como un relicario familiar, guarda celosamente las modestas y valiosas tradiciones arquitectónicas de nuestra provincia. Tan ejemplar conducta no ha impedido que nuestro ilustre paisano edifique en otros sitios "a la moderna", con todas las ventajas del cemento y el hierro industrial, pero con las caracteristicas que imponen los materiales tradicionales y el modesto medio en que se vive.

Es conveniente e indispensable que el Gobierno de nuestro Estado, de cuyo espíritu progresista son muestras claras -entre otras muchasla erección de nuestra flamante Universidad, el patrocinio de la III Asamblea de este $H$. Congreso de Instituciones Culturales y la creación de la Dirección de Turismo del Estado de México, seleccione y resguarde bajo una protección legal adecuada la casa colonial popular de Toluca, que en sus ejemplares más típicos representa las más caras virtudes provincianas. 